\title{
Médecins Sans Frontières moves to protect refugee healthcare
}

\begin{abstract}
As Médecins Sans Frontières (MSF) spurned all European Union (EU) funding for its projects worldwide after a series of cynical EU-country moves to choke inward refugee flow, South African (SA) activists in Johannesburg this June protested the proposed stiffening of local refugee laws.

The People's Coalition Against Xenophobia, consisting of MSF, the Africa Diaspora Forum, Lawyers for Human Rights, Section 27 and a host of other related NGOs, intervened in various xenophobic crises that erupted across the country in 2008 and 2015, providing emergency healthcare and successfully improving healthcare access. Explaining the Coalition's 18 June protest, Dr Borrie le Grange, MSF's SA communications chief, said that the proposed Refugees Act Amendment Bill wanted to move refugee centres closer to the country's borders and reduce the time they had to apply for refugee status by nearly two-thirds ( 14 days to 5 days) from when they entered the country. Asylum applications would be based on a refugee's ability to sustain him- or herself and any dependants with the help of family or friends for at least 4 months, while limiting or prohibiting him or her from working. This rolled back the rights of refugees, who MSF
\end{abstract}

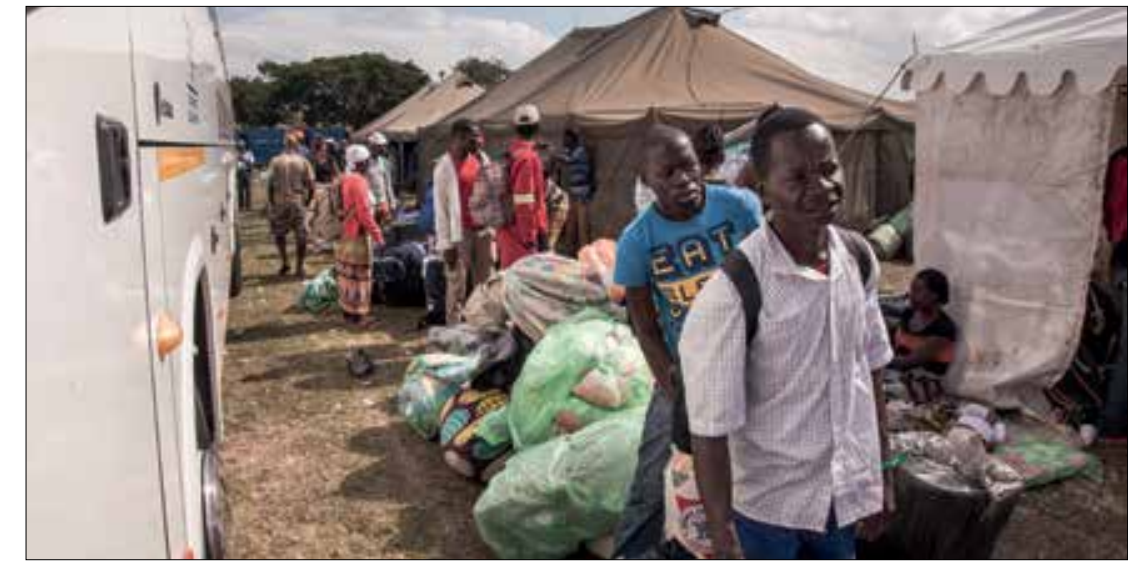

April 22, 2015 - fugitives of xenophobia. Malawians line up to catch buses home from displacement camps around Durban. Source: MSF.

had learnt from working with them at the Central Methodist Church in Johannesburg (2008 - 2013) were reluctant to seek official healthcare, with provincial healthcare staff demanding 'green ID books' before treating anyone. 'They've often been attacked or raped in getting here and finding food, shelter and employment take precedence over medical care', he explained. MSF, through its primary healthcare interventions and accompanied referrals, had compelled health authorities in Johannesburg to change staff attitudes and care to comply with basic human rights.

SA has 1096063 pending cases of asylum seekers, an increase from the 463900 reported previously by government, says the United Nations Commission for Refugees.

\section{Chris Bateman}

chrisb@hmpg.co.za

S Afr Med J 2016;106(8):747.

DOI:10.7196/SAMJ.2016.v106i8.11229 